\title{
Valores del paisaje en la vida cotidiano de los cafeteros, referentes para la gestión sustentable del patrimonio territorial en el Quindío, Colombia²
}

- Recepción: 28 de enero de 2027 - Evaluación: 07 de abril de 2027 • Aprobación: 21 de junio de 2027

Resumen: El rol de los habitantes rurales en la conformación de paisajes agrarios y patrimonios, en muchas definiciones y acercamientos, está reducido a su influjo histórico. En el estudio, no obstante, se pone en primer lugar a los caficultores en su actuar cotidiano en relación con el paisaje cultural. Los objetivos investigativos focalizaban el interés emic en los valores y significados que los productores cafeteros asignan a la finca. A partir del estudio cualitativo con enfoque fenomenológico-interpretativo que usó la entrevista a profundidad y la observación participante como principales instrumentos, se identificaron valores y significados que dan sentido a la vida cotidiana y las condiciones en que se dan los procesos de apropiación del patrimonio rural en torno al arraigo histórico-espacial y sociocultural. Esta exteriorización de los significados da a entender la complejidad de procesos de valoración, resignificación y reivindicación a partir de los cuales se proponen lineamientos para la gestión sostenible del paisaje patrimonial.

Palabras claves: valores patrimoniales, productores cafeteros, significados, paisaje cultural.

Para citar: Duis, U. (2021). Valores del paisaje en la vida cotidiano de los cafeteros, referentes para la gestión sustentable del patrimonio territorial en el Quindío, Colombia. Perspectiva Geográfica, 26(2), 54-71. https://doi.org/10.19053/01233769.12404 


\title{
Landscape values in the daily life of coffee growers, references for the sustainable management of the territorial heritage in Quindío, Colombia
}

\begin{abstract}
The role of rural inhabitants in shaping agrarian landscapes and heritages, in many definitions and approaches, is reduced to their historical influence. In the study, however, coffee growers are put first in their daily actions in relation to the cultural landscape. The research objectives focused emic interest on the values and meanings that coffee growers assign to the farm. From the qualitative study with a phenomenological-interpretative approach that used in-depth interviews and participant observation as main instruments, values and meanings were identified and they give meaning to daily life and the conditions in which the processes of appropriation of the rural patrimony take place around the historical-spatial and socio-cultural rootedness. This externalization of meanings gives an understanding of the complexity of processes of valuation, resignification and vindication from which guidelines are proposed for the sustainable management of the heritage landscape.
\end{abstract}

Keywords: heritage values, coffee producers, meanings, cultural landscape.

\section{Valores da paisagem na vida cotidiana dos cafeteiros, referentes para a gestão sustentável do patrimônio territorial em Quindío, Colômbia}

\begin{abstract}
Resumo: O papel dos habitantes rurais na conformação de paisagens agrárias e patrimônios, em muitas definições e aproximações, está reduzido a sua influência histórica. No entanto, no estudo põe-se em primeiro lugar aos cafeicultores no seu comportamento quotidiano em relação à paisagem cultural. Os objetivos investigativos focalizavam o interesse emic nos valores e significados que os produtores cafeteiros atribuem à propriedade. A partir do estudo qualitativo com enfoque fenomenológico-interpretativo que usou a entrevista em profundidade e a observação participante como principais instrumentos, identificaramse valores e significados que dão sentido à vida cotidiana e as condições em que se dão os processos de apropriação do patrimônio rural em torno do enraizamento histórico-espacial e sociocultural. Esta exteriorização dos significados dá para entender a complexidade de processos de valorização, ressignificação e reivindicação a partir dos quais se propõem diretrizes para a gestão sustentável da paisagem patrimonial.
\end{abstract}

Palavras-chave: valores patrimoniais, produtores cafeteiros, significados, paisagem cultural. 


\section{Introducción}

El Paisaje Cultural Cafetero de Colombia (PCGC) ha sido inscrito en la Lista de Patrimonio Mundial de la Unesco en 2011. Está ubicado en las franjas

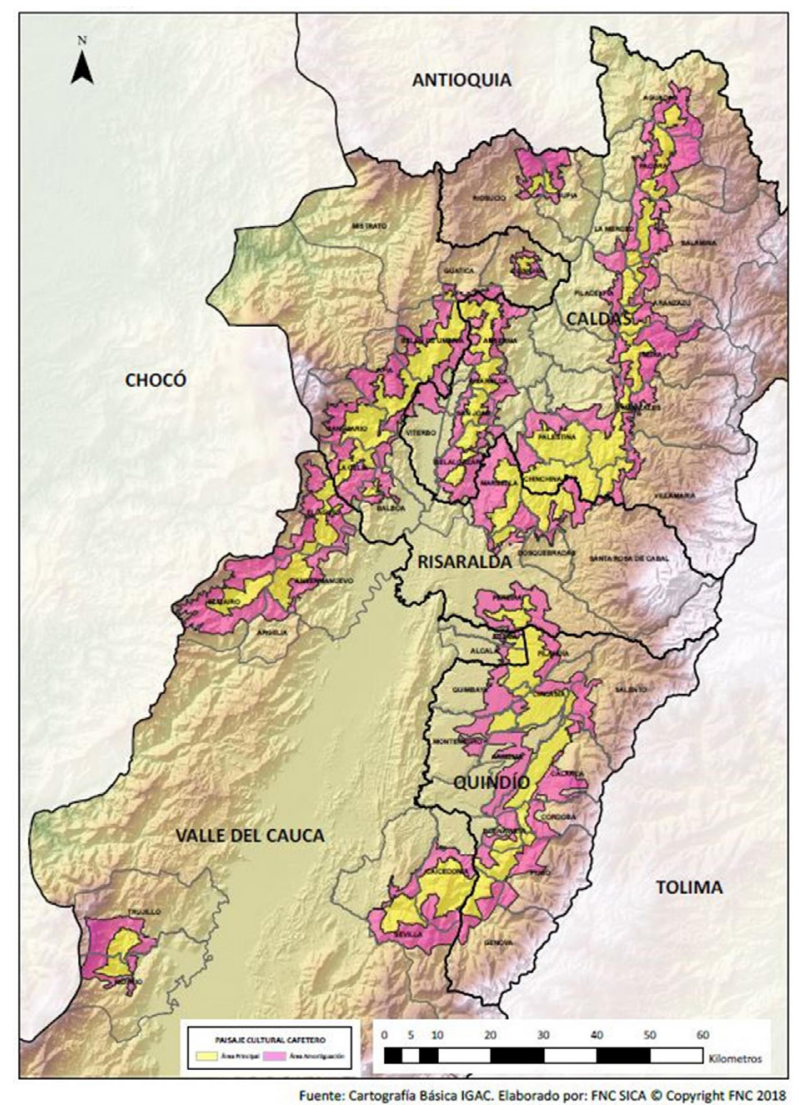

occidentales de la cordillera Central y las franjas orientales de la cordillera Occidental del Cauca Medio y comprende municipios y veredas de los departamentos de Caldas, Risaralda, Quindío y Valle del Cauca de Colombia (Figura 1).

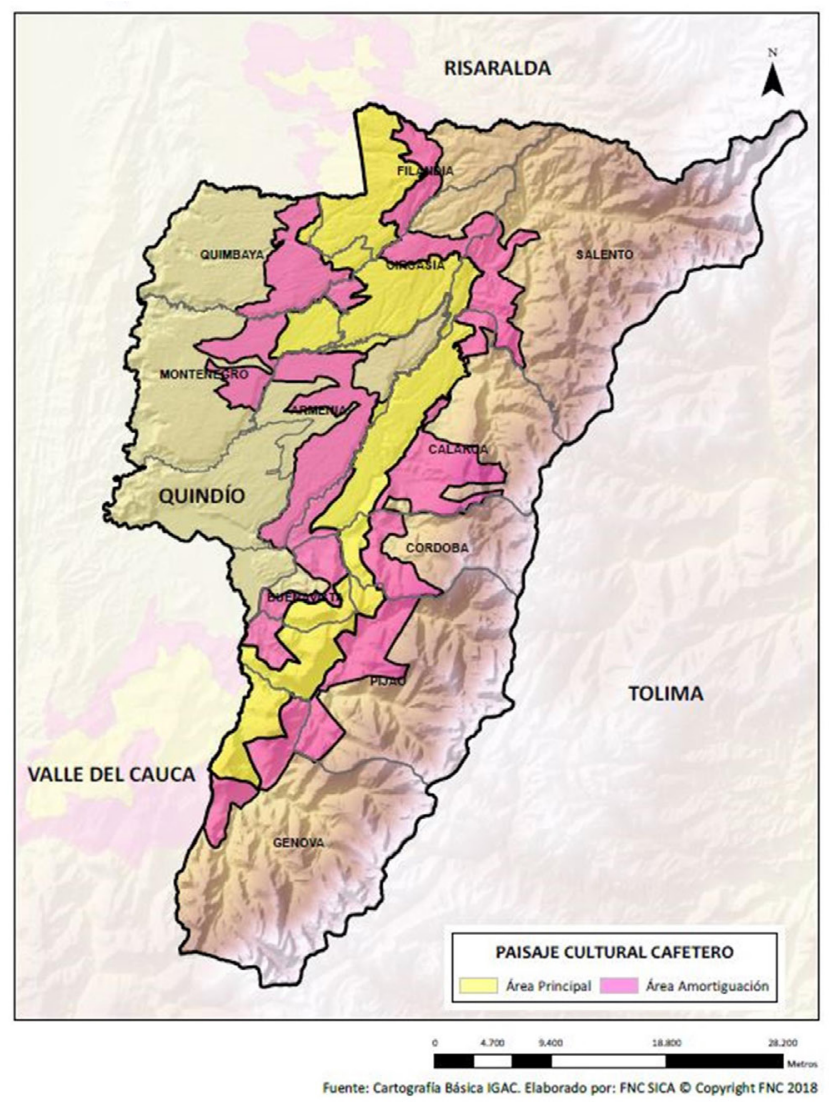

FIGURA 1. Ubicación del Paisaje Cultural Cafetero y detalle del Quindío FUENTE: Ministerio de Cultura \& Federación Nacional de Cafeteros (FNC) (2018).

El Quindío, uno de los cuatro departamentos del PCCC, está dividido en doce municipios y once de ellos tienen veredas incluidas en el área del Paisaje Cultural Cafetero. Geomorfológicamente, en el departamento se distinguen claramente dos zonas: el plan del centro-occidente y la zona cordillerana del oriente, al sur. De las 267 veredas del Quindío, 207 son cafeteras y 128 hacen parte del PCGC (Ministerio de Cultura \& Federación Nacional de Cafeteros [FNC], 2009). En su uso de suelo rural domina el café y su área ascendía a 46.107 hectáreas en 2008, fecha de delimitación del área a proteger. No obstante, su valoración patrimonial, diez años más tarde se reportaron solo 21.600 ha
(2008) para todo el departamento, lo que indica un fuerte descenso en este uso de suelo.

Según el expediente (Ministerio de Cultura \& FNC, 2012), el valor universal excepcional (VUE) del PCCC consiste en una combinación de valores históricos, productivos, sociales, culturales y ambientales definidos por los grupos de trabajo conformados por universidades e instituciones gubernamentales. Pero en su formulación se evidencia una escasa integración de la perspectiva de sus habitantes (Duis, 2007; 2009) y la ausencia de procesos que buscan comprender los significados en las fincas cafeteras (Duis, 2020). Esta situación llevó a determinar valores culturales como el 
folclor musical, las creaciones artísticas y literarias y las artesanías, entre otros, procedentes del discurso oficial de la conformación de los departamentos de Caldas, Risaralda y Quindío, pero que, en la cotidianidad, como se comprobó (Duis, 2020), tienen poca presencia en las fincas cafeteras. En contraste, hay elementos de gran valor cultural, social, productivo y ambiental en las fincas que no se reconocen oficialmente como valor patrimonial, pero que son vigentes y significativos para los habitantes cafeteros. De ahí la brecha entre los valores estipulados en el expediente del PCCG (Ministerio de Cultura \& FNG, 2012) y los valores que asignan los cafeteros a sus prácticas y espacios en la cotidianidad, situación que restringe una acción articulada para la sostenibilidad del territorio patrimonial.

Ahora bien, comprender significados de una cultura, según Geertz (1973), pasa a través de la descripción densa de los quehaceres de la gente e implica examinar conductas y propiedades y no solamente el sistema simbólico u objetos aislados que conforman la cultura. Por lo tanto, en el marco del estudio se propuso un análisis cultural de la vida cotidiana de los cafeteros donde los valores y significados se visibilizan en las trayectorias y vivencias en su paisaje. Los valores se consideran patrimoniales cuando son constantes, apropiados y repetidos y corresponden a las apreciaciones e interpretaciones propias de la realidad subjetiva. Los valores se dotan de significados en la vida cotidiana, escenario que "se constituye por aquellas prácticas, lógicas, espacios y temporalidades que garantizan la reproducción social por la vía de la reiteración" (Reguillo, 2000, p. 78). Su análisis permite teorizar sobre el arraigo espacial, histórico, cultural y social del cafetero, también llamado "anclaje territorial" (Sereno, 2020), que le permite persistir en la producción cafetera.

\section{Aristas de una discusión dinámica e inconclusa}

El patrimonio cultural no solo es huella, legado o acervo, sino que se entiende hoy en día más como construcción social (Llull, 2005; Guerrero Valdebenito, 2014; González, 2015). La construcción del patrimonio es, según Adad (2010), una operación dinámica, enraizada en el presente, a partir de la cual se reconstruye, selecciona e interpreta el pasado; es la invención a posteriori de la continuidad social. Hobsbawn y Ranger (1983) hablan de la construcción del patrimonio como interpretación a partir de la recuperación de elementos tangibles del pasado o prácticas culturales que "aseguren o expresen cohesión e identidades sociales y estructura en las relaciones sociales" (p. 273). Desde esta perspectiva, se puede hablar de un proceso artífice. Prats y Santana (2005) interpretan el patrimonio como un activo o recurso de primera importancia, lo que implica su mercantilización. Esta forma de patrimonialización es problemática, ya que escasamente incluye a todos los actores (Guerrero Valdebenito, 2014; Sepúlveda Manterola, 2004; Guerra \& Skewes, 2008; González, 2015). Se aíslan las tradiciones, las costumbres, las prácticas y los bienes materiales, entre otros, de su entorno originario, reduciendo el patrimonio a unos objetos representativos que no captan la esencia de los procesos sociales y culturales que engloban la generación de patrimonio.

A diferencia de estos acercamientos utilitaristas, se encuentran enfoques conducentes a la integración de la gente en procesos participativos. González (2015) describe el patrimonio como un bien común (a common), realzando el valor de lo público, social y participativo, y Smith (2006) lo define como un proceso cultural que implica actos de "recordar" (remembering) que a su vez se relacionan con el presente, donde los sitios o espacios específicos figuran como instrumentos para facilitar este proceso. El patrimonio, en este orden de ideas, es algo vital y vivo, es experiencia, es identidad, es subjetivo e intangible, es un proceso constitutivo cultural que identifica cosas y lugares aptos para la valoración.

Ahora bien, el paisaje cultural como patrimonio muestra grandes diferencias en su conceptualización y entendimiento, lo que muestra la carencia de una 
adecuada tematización de la relación entre el patrimonio, el territorio, la naturaleza, el paisaje y sus habitantes. El paisaje cultural es, según Fernández y Silva (2016), un campo teórico emergente en materia de bienes culturales a pesar de contar con gran reconocimiento, actualidad e innumerables estudios y conceptualizaciones (Maderuelo, 2006; Nogué, 2007; Berque, 1997; Cano Suñén, 2011; Ulloa, 2002). Desde una perspectiva fenomenológica, el paisaje se considera como una construcción simbólica y social, una experiencia humana que implica las determinaciones culturales, sociales e históricas de la percepción de un observador. La concepción del paisaje agrícola engloba en su concepción los valores y los bienes agrarios (Castillo Ruiz, 2015) sin considerar a sus principales actores. En el pensamiento hermenéutico, al contrario, el paisaje incluye la perspectiva histórico-social, es decir, la interacción entre sociedad y naturaleza a través del tiempo (López, 2004 y Márquez, 2000, citados en Cano Suñén, 2011). Esto es especialmente importante porque "el paisaje no solo constituye uno de los más elaborados productos de la cultura, sino que $[\ldots]$ es en sí mismo cultura y patrimonio" (Martínez de Pisón, 2002, citado en Silva, 2009, p. 322). El paisaje, en este sentido, "está imbricado con las maneras de vivir el territorio, los movimientos de sus gentes, sus prácticas o sus trabajos y, por tanto, su fisionomía persiste sólo en la medida en que estas actividades continúan" (Cano Suñén, 2011, p. 37). Hablar del paisaje y del patrimonio implica por tanto integrar a los habitantes que lo forman y describir la cultura más allá de los símbolos y las representaciones que se consideran identitarios.

Según estos planteamientos, considerar el patrimonio y el paisaje cafetero como una relación sensible y cotidiana de los habitantes con su entorno implica identificar y reconocer los valores en la vida cotidiana. El estudio aquí presentado se centra por lo tanto en el valor intrínseco e intangible que los cafeteros adjudican - consciente o inconscientemente - a sus quehaceres en su diario vivir. Lo que interesa no es la acción política institucional de patrimonialización que se centra en objetos y elementos representativos, sino el valor otorgado por los mismos habitantes locales a lo propio y sus significados, que permiten conservar las prácticas que dan vida al patrimonio.

Los valores pueden ser variables, adaptados y modificados dependiendo de su apropiación por el grupo familiar y social; de todos modos, sus interpretaciones pueden variar según la situación histórica y social, el espacio y el tiempo. El valor (del lat. valor, -ôris) del patrimonio se refiere a una relación o una cualidad (Vargas, 2002, citado en Duis et al., 2010), es el grado de utilidad o aptitud de las cosas para satisfacer las necesidades o proporcionar bienestar o deleite, se relaciona con usos, funciones y utilidades que pueden proveer un bien patrimonial, pero también se usa para hablar de lo simbólico, lo emocional, lo cultural o lo histórico de las cosas. En la literatura (Lennon, 2002; Folch \& Bru, 2017; Ojeda Rivera, 2013; Mármol et al., 2010) se distingue una serie de valores asociados a un paisaje, como los estéticos, naturales y ecológicos, productivos, sociales, históricos, espirituales y mitológicos, emocionales, sensoriales, simbólicos e identitarios, colectivos, funcionales, de memoria y de bienestar, entre otros. En general, cada sociedad reconoce en el paisaje y el patrimonio diferentes valores, los cuales evolucionan con el imaginario colectivo y no necesariamente se perciben de manera homogénea entre todos los grupos sociales (Duis et al., 2010). Lo que tiene valor es lo que se desea transmitir a las siguientes generaciones, lo que es - en el mejor de los casos - pilar fundamental para una cultura local e identidad cultural. Según Querejazu (2003), "El patrimonio cultural tiene un valor real y simbólico para el grupo humano que lo ha heredado. En consecuencia, el patrimonio cultural no vale en sí mismo sino porque el grupo humano le da valor" (p. 22). Esta asignación de valor responde a las necesidades de un grupo social y a los cambios de paradigmas culturales. En este sentido, no hay valores absolutos, "son conceptos éticos, socialmente cambiantes, aceptados y deseados 
como ideales en un determinado contexto social e histórico" (Caraballo, 2011, p. 26). Además, los valores son subjetivos y dinámicos, y, por tanto, relativos, pues no existe un estándar donde todos los individuos tengan una percepción unánime. Los valores, en consecuencia, no son homogéneos ni inalterables.

En el caso de las fincas cafeteras, la asignación de valores, en su mayoría, se hace de manera inconsciente con consecuencias prácticas en la cotidianidad en la cual se reproducen, por cuanto son invisibles, inherentes y cotidianos. La reproducción se entiende, según Bourdieu (1988), como el conjunto de prácticas por medio de las cuales los individuos y las familias tienden de manera consciente o inconsciente a conservar su patrimonio. Esta reproducción, a su vez, se relaciona con los procesos en torno a las memorias y los horizontes de futuro, los cuales, según León Vega (1999), se "recrean y reconstruyen [por los sujetos] para darle a sus vidas un sentido, vale decir, contenido, dirección y ritmo" (p. 16). En los procesos cotidianos, se define lo que es legítimo, normal y necesario para garantizar la continuidad de una cultura. En esta acción se crean los significados culturales, validados y legitimados por procesos de creación y recreación de un sentido que los relaciona con el pasado (Smith, 2006).

En la actualidad, el término "significado" no se encuentra claramente definido y se usa frecuentemente igual que el término "valor" al referirse a un bien patrimonial (Manzini, 2011, p. 27). Cirvini (2019) sostiene que hay un escaso tratamiento sistemático y científico de los conceptos. Aunque las cartas y recomendaciones internacionales tienden a usar los dos términos, valor y significado, con cierta equivalencia, el trabajo de campo muestra que el valor se ubica más en lo funcional utilitario que ordena las estructuras. El significado, adicional a este, explica la razón de ser, es la interpretación de un elemento patrimonial desde la perspectiva del portador. Se genera, por lo general, mediante un proceso subjetivo, cognitivo, consciente, en relación con la acción social, es una interpretación de los valores en relación con las vivencias cotidianas, el espacio y el tiempo.

En este sentido, se plantea que el significado de un sitio existe en la mente de las personas que lo reconocen y aprecian. Corresponde, en cierta manera, a las asociaciones que se asignan a ciertos elementos que se valoran en la vida cotidiana, que nacen de las interpretaciones propias y subjetivas. El significado permite, según Manzini (2011), “comprender la razón de ser de un elemento patrimonial en el tiempo, [...] explicar el elemento patrimonial como producto cultural y su relación contextual, [y] fundamentar la sostenibilidad del elemento patrimonial" (p. 33). Valor, significado y sentido conforman una trilogía que da sustento a la conservación de las fincas cafeteras (Figura 2).
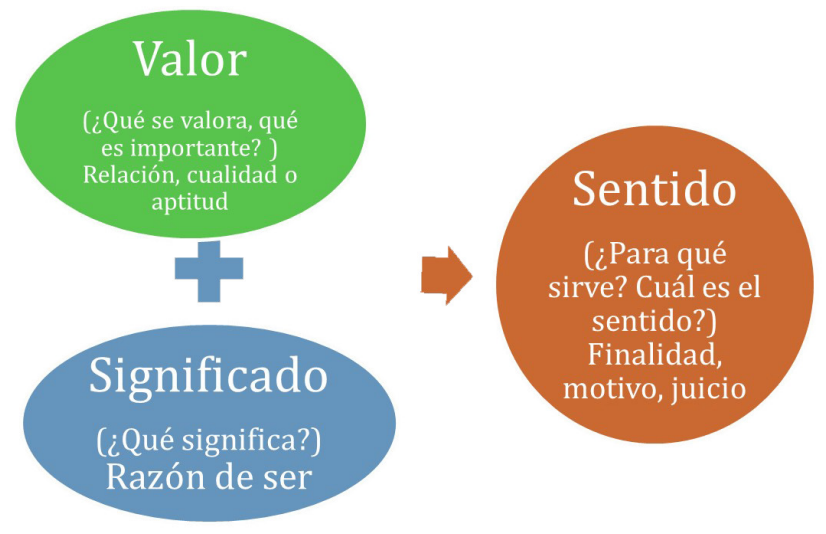

FIGURA 2. Trilogía: valor, significado y sentido

FUENTE: elaboración propia. 
Es importante anotar que este estudio no se centra en los valores visibles o los elementos tangibles con los cuales comúnmente se caracteriza o describe un paisaje, sino en los valores y significados que lo sostienen a partir de una valoración de sus habitantes. Muchas veces no se identifican de manera explícita, precisamente porque son cotidianos o "normales". Hacer visibles estas valoraciones es importante para la gestión sostenible que tendría que procurar integrar y reconocer más explícitamente a los cafeteros y sus prácticas culturales.

\section{Enfoque metodológico- conceptual}

Geertz (1973) indica que la cultura que se transmite es patrimonio, es lo que hace vivir, sentir y actuar. Conocer los valores a partir de los quehaceres culturales abre la puerta a una mayor comprensión de los procesos culturales y sociales que explican las persistencias y que permiten conocer e incidir en los mecanismos de apropiación y reproducción del patrimonio en la vida cotidiana del mundo cafetero. La estrategia metodológica se orientó, en este orden de ideas, a investigar los valores y significados en la cotidianidad de los caficultores y su grupo familiar. Desde este planteamiento, lo cotidiano se constituye en el lugar donde se realiza la vivencia subjetiva y la producción y reproducción de las estructuras sociales y culturales.

Bajo este razonamiento, comprender valores en un contexto histórico, cultural y social implica una investigación con perspectiva histórica-narrativa y biográfica
(Cornejo, 2006) que visibiliza las trayectorias subjetivas e individuales de los caficultores. Las fincas cafeteras son el espacio de proximidad en el cual, según Schütz, se construyen los significados intersubjetivamente, es decir, se construyen considerando al otro y en interacción con el otro (Hernández \& Galindo, 2007). En este orden de ideas, entender los fenómenos sociales desde la propia perspectiva del actor que es protagonista del estudio motivó la elección del enfoque fenomenológico-interpretativo que permite abordar cómo los sujetos vivencian los elementos constitutivos del paisaje cafetero en su unidad mínima: la finca cafetera.

Los instrumentos aplicados son la observación participante, que permite visualizar formas de vivir y costumbres constituyentes de la vida cotidiana, y la entrevista a profundidad, la cual, en su aplicación, se convierte en relato de vida. Este enfoque narrativo es útil para comprender la ontología de lo intangible de la cultura y visualizar lo que se entiende y vive de la cultura cafetera para cristalizar los elementos que la componen.

En total se visitaron 26 fincas del Quindío, pertenecientes a un total de siete municipios. Se interactuó con un total de 43 personas, en conversaciones individuales y grupales, con edades entre 34 y 86 años. Se incluyeron propietarios de micro (menos de 1 ha, 3 casos), pequeñas (1-10 ha, 14 casos), medianas (1050 ha, 4 casos) y grandes fincas (más de 50 ha, 5 casos). Las conversaciones con los cafeteros giraron en torno a valoraciones relacionadas con la historia de la finca, la familia, la caficultura y las prácticas culturales en su entorno sociocultural (Tabla 1).

\section{TABLA 1. Categorías y variables}

\begin{tabular}{|ll|}
\hline & \\
\hline \\
Valoración histórica & Historia de la finca \\
& Historia de la familia \\
& Historia personal \\
& Significado de la tierra y de la finca \\
\hline
\end{tabular}




\begin{tabular}{|ll|}
\hline \multicolumn{1}{|c|}{ Categorías } & \multicolumn{1}{c|}{ Variables } \\
\hline Valoración productiva & Modelo de producción cafetera \\
& Ingresos complementarios \\
& Toma de decisiones \\
& Significado del café \\
& Orgullo del cafetero y reconocimiento \\
& Expectativas y motivos \\
\hline Valoración familiar y social & Composición familiar \\
& Condiciones sociales \\
& Procesos educativos \\
& Decisiones/autoridad \\
\hline Valoración cultural & Tradiciones y costumbres \\
& Prácticas en una jornada laboral \\
& Características del cafetero \\
& Forma de vivir/“filosofía” \\
\hline & Significado de la finca \\
\hline & Relaciones con los vecinos \\
& Presencia institucional \\
& Posición frente a la institucionalidad \\
\hline
\end{tabular}

FUENTE: Duis (2020).

La sistematización de los datos a partir de las regularidades e irregularidades encontradas encauzó en grupos de significados a partir de los hallazgos de tipo emic, es decir que se adopta la perspectiva de los actores rurales entrevistados. Algunos aspectos relevantes para el análisis de la información fueron: 1) la importancia de centrar la atención en la historia como un todo, y aunque los valores y los significados se extraen de las vivencias, se busca no desconectarlos de las interpretaciones que las personas hacen de sus vidas en los contextos narrativos, temporales, emocionales, relacionales e interaccionales en que se producen (Bernasconi, 2011); 2) la necesidad de volver a insertar los valores y significados individuales en el contexto social en el que surgen, dada la importancia de trascender lo particular y de construir un saber más denso sobre lo social (Kornblit, 2007); y 3) la necesidad de abordar la vida en el marco de la historia de la finca para luego adoptar una lógica transversal, que permita determinar ejes temáticos-analíticos relevantes y teorías comprensivas transversales (Cornejo, 2006). Estos pasos corresponden a los niveles de significados que menciona Schütz (1932, citado en Hernández \& Galindo, 2007), a saber: el nivel del actor solitario, el nivel que implica a otro, el nivel de interpretación de conductas, el nivel de orientación de la acción y el nivel del observador. El análisis de estos niveles permite derivar categorías a partir de aspectos comunes y componentes centrales en un proceso itinerante inductivo. La comprensión interpretativa en este proceso analítico es concebida como un proceso hermenéutico en el cual la experiencia humana depende de su contexto, que permite trascender lo particular (Matijasevic Arcila, 2015). Esta interpretación se sostiene en el sentido común, la comprensión filosófica, la reflexión y las analogías desde la experiencia propia de vida rural y campesina. Según esta estructura, se procedió a identificar valores y significados siguiendo la codificación abierta inicial que luego se amplió en el proceso de permanente recodificación e integración de categorías, poniéndolos posteriormente en contexto histórico, productivo, familiar y social e interpretando los hallazgos.

\section{Valores y significados del paisaje en la cotidianidad de sus habitantes}

La investigación permitió identificar los valores patrimoniales y sus significados en la vida cotidiana de los 
cafeteros que producen y reproducen el paisaje en los componentes productivos, sociales, culturales y ambientales que se describen a continuación.

\subsection{El paisaje es memoria y la memoria en el paisaje}

El paisaje cafetero es memoria que se nutre de la historia de colonización por familias de Antioquia, Cauca, Tolima y Cundinamarca, para mencionar algunas de las procedencias. En los relatos sobre la historia de la finca se hace referencia a la llegada de los ancestros como un valor histórico que une a la familia y que también une la familia a la tierra. Este proceso histórico ha generado orgullo y pertenencia a este espacio, como destacan varios de los entrevistados. Frases como "esto fue colonizado por mi abuelo" o "aquí mi abuelo compró una mejora" dan constancia de esta historia "apropiada", una apropiación que genera identidad y arraigo.

En cuanto a la propiedad de tierra que surge de la ocupación del territorio desde finales del siglo XIX y principios del siglo $\mathrm{xx}$, se puede indicar que genera reconocimiento social y pertenencia a un grupo social. En las narrativas se refiere a "propiedades grandes, todo esto era de una sola familia". Tener propiedad grande implicaba obligaciones para disminuir las diferencias sociales. Fue así como antiguamente se donaron lotes para obras comunitarias. En estos casos, la propiedad dio lugar a una vida comunitaria entre familias extensas con parentesco o vecindad de lugares de origen.

Doña Nubia $^{3}$ (Finca B.A./P., F87) es uno de los testigos de este pasado y con fervor cuenta que "El abuelo tumbó monte. Esto fue colonizado por mi abuelo, vino de Antioquia, mi papá nació acá, todos nacimos aquí". Esta historia familiar asociada a la finca da cuenta de la valoración emocional, histórica y social del predio como centro de vida, especialmente cuando sus integrantes nacieron ahí.

3 Por cuestiones de confidencialidad, los nombres fueron cambiados. El código indica la finca, su ubicación en el plan (P) o cordillera (C), el sexo del entrevistado y su edad.
La tierra, fuera de ser insumo productivo, es, según algunos entrevistados, "amor, abrigo, es mamá de nosotros que nos dio todo, la finca significa libertad, aire libre, es seguridad, tranquilidad, calidad de vida, salud, disfrute, buenos productos, alegría y vida". Es una personificación de los aportes que responden a necesidades como seguridad, amor, bienestar y subsistencia. En la muestra, especialmente las mujeres luchan por conservar la herencia, la tierra es centro de las familias y punto de encuentro, pero también les permite autonomía y pervivencia, significados específicos destacados en casos de violencia intrafamiliar en los cuales la herencia se convierte en refugio. Mantener la tierra en los procesos de sucesión cobra especial importancia en memoria a los ancestros y el valor de la tierra y la convivencia. Al respecto, Nubia cuenta: "Entonces partimos la tierrita para que cada uno cultivara lo que le pertenecía. Pero la casa la dejamos para todos y vivimos todos junticos aquí".

Los caficultores empresariales ausentistas también tienen esta adscripción a la tierra, aunque bajo otras modalidades y objetivos. La identidad cafetera para ellos, si bien se relaciona con la propiedad de tierra y la producción de café, más que todo se conforma a partir del éxito económico; en consecuencia, ellos buscan en sus fincas mayor productividad y rentabilidad.

En otro caso, con esfuerzo, trabajo y dedicación se logró ascenso social, estatus y bienestar. Esto ha sido clave para hacer parte de la sociedad cafetera y política que se nutre de las propiedades. Mayra (Finca C./P., F/52) indica que hasta que su padre no hizo negocios y compró fincas, no se pudo casar con la prometida de clase alta.

La finca se refiere tanto a la tierra como a la casa. En este sentido, Pablo (Finca B.A/P., M45) indica que el hogar es el lugar de apego y de afecto: "Uno llega a la casa, el apego a la casa tiene que ver con la familia, uno llega a un hogar y siente cómo baja el estrés que trae. Es esta parte del arraigo, cuando en la casa encontramos abrigo, en la tierra encontramos comida, 
productos de subsistencia, todo". La casa, este espacio geográfico, se convierte en lugar de significados donde se establecen reglas, normas, convivencias, historias, relaciones y rutinas, lo que remite a los quehaceres y saberes en torno a la finca cafetera. Asimismo, la casa se convierte en anclaje y punto central para la vida familiar y social.

En el caso de los cafeteros ausentistas se da una aproximación distinta. Los ámbitos de actuación de vivir, ser y trabajar se diferencian porque el trabajo implica desplazamiento, lo que resulta en que la finca no adquiere las mismas connotaciones y significados.

En resumen, se evidencia que el origen histórico de las fincas, que data de los siglos XIX y XX, es un elemento importante en la apropiación del espacio. La memoria y la propiedad de la tierra, unidos a la historia familiar e individual, son el sustrato en el cual se cultiva el arraigo espacial-histórico y sociocultural. Las narraciones denotan un espacio de proximidad que está íntimamente relacionado con la dinámica familiar y sus eventos. De la noción histórica se deriva el significado de la finca como hogar que expresa la dimensión emocional-familiar y cultural.

Sus valores, hoy en día, se encuentran amenazados por la desagrarización, la "nueva colonización" por turistas y pensionados y la gentrificación del territorio, que aceleran los cambios estructurales y el abandono del campo. Esto puede tener implicaciones en el paisaje en su aspecto físico-visual y su composición sociocultural y, por ende, en la sustentabilidad del patrimonio.

\section{2. "El café en las venas"}

El café, en muchas de las fincas, se considera como "cultivo principal", como asegura Amanda (Finca El E./P., F/65): "Del café vivimos, no hay pensión ni nada, es la única forma de sobrevivir, obligatorio. Es el sustento". Para las pequeñas fincas gran parte del ingreso monetario se deriva del café, y para las grandes fincas es importante porque son las de mayor cobertura en café. Por lo tanto, el café tiene un valor económico funcional. La mayoría de los cafeteros entrevistados, independiente de la estructura de costos y del tamaño de finca, tienden a diversificar y no especializar ante la dificultad de mantener flujo de caja. No quieren salir del café por la inseguridad que implican otros cultivos de ciclo corto.

Gran parte de los caficultores de pequeñas fincas tienen una relación con el cultivo emocional-subjetiva y personalizada, que supera los aspectos económicos. El café, además de constituir una fuente de ingresos para la subsistencia, es tradición, es memoria, es gusto, es trabajo en el sentido de ocupación, es lo que se sabe hacer desde la niñez, es actitudy esperanza, es gratitud, es superación y dedicación. Con el café, se tiene un especial afecto que compensa los bajos precios. Emilio indica: "Café, eso lo tenemos en las venas, es como en la ADN [sic]".

Tenerlo "en la sangre" significa que es parte de uno, del cuerpo y de la vida. Es lo que uno es y lo que sabe hacer, "es lo que uno va aprendiendo en el campo". Es definición de uno porque forma parte del saber, hacer, sentir y ser. Estos diferentes afectos incidentales, sufridos o disfrutados están definiendo las relaciones con el café que evocan los valores y las actitudes que trabajan a favor del patrimonio. Este patrimonio es lo que ocurre cuando las emociones se relacionan con la historia y las prácticas diarias, razonan sobre la esencia de la vida, la dinamizan o la transforman. El café es un gusto, pero también es pasión. No solo es el sabor del producto final, sino el gusto de trabajar el café, como indica Ruth: "Otra cuestión que se ha conservado es que somos mujeres que nos gusta trabajar, no es para nada una deshonra a coger café".

Ser cafetero, para muchos, significa hacer parte de un grupo social que implica un compromiso social y hacer parte de una identidad cafetera. La pertenencia social se muestra en la conformación de los comités y cooperativas de café, pero también en las asociaciones y las instituciones culturales que hacían o hacen 
parte de la vida cultural de los cafeteros. En cierta manera, la homogeneidad de la estructura rural permitió conformar una identidad cultural basada en "lo igual", pero también se conforma identidad cultural, en especial en las zonas apartadas, sobre la diferencia cuando de productores de café especial se trata. Esta diferencia se da especialmente en respuesta al discurso oficial del PGCG que invisibiliza a las mujeres cafeteras, lo que genera un decidido rechazo del discurso oficial. Esto se plantea en la voz de Beatriz (Finca E.O./C., F65), que quiere "contar la verdadera historia de este paisaje. Las mujeres tienen que ver con todo [el paisaje], pero desaparecimos. El centro de esta cultura ha sido la mujer. [...] El paisaje nos ignoró, nos indignó del todo. [...] El paisaje [cultural cafetero] nunca menciona la resistencia, las crisis que hemos vivido, jamás ha encontrado lágrimas de mujer" (Entrevista personal).

Según ellas, la distinción de una "cultura cafetera" como expresión del folclor es indudablemente insuficiente como concepto identitario que motiva la apropiación, ya que se percibe como algo impuesto y excluyente y no se ha concertado ni ajustado a la situación vivida por ellas.

El paisaje tiene una función productiva, pero los modelos de producción - diversos y diversificadosse adaptan a las condiciones de cada finca y los gustos de sus propietarios, generando modelos de producción "con sentido" desde sus diferentes ámbitos y posibilidades. Se muestran diferentes dimensiones de pensar el negocio del café, que se adaptan a los desiguales recursos a partir de los cuales los cafeteros se confrontan con sus patrimonios y se apropian del paisaje. Consta que una buena parte de la población siembra el café por costumbre, conservando así el patrimonio familiar y dando un sentido a su tiempo libre con una ocupación que les gusta. El café, excepto en los casos de una caficultura empresarial, está asociado al trabajo acostumbrado que se realiza porque es lo que aprendieron de sus padres. Las transformaciones en el uso de suelo, no obstante, inciden en el abandono del campo por parte de sus productores e hijos, lo que afecta el paisaje en la conformación social y económica.

\section{3. "La cultura la somos nosotros"}

Los resultados permiten evidenciar que aspectos usualmente invisibilizados por quienes hacen una lectura externa de la cultura cafetera son de alta relevancia para los productores de café, en términos de la reproducción y la sostenibilidad de la cultura. Se halló que las rutinas diarias, las formas de relacionarse y convivir con los otros, las maneras de preparar y compartir los alimentos y la vivencia comunitaria en torno a las creencias, entre lo más mencionado, corresponden, en el plano de la vida cotidiana, a los valores que hoy otorgan sentido a lo que significa "ser y sentirse cafetero".

En torno a la alimentación diaria hay un mundo que se desarrolla desde las huertas donde se cultivan los productos, pasando por las cocinas, los medios de cocción, las formas de preparación, los ritmos y los horarios de las comidas, las reglas y las costumbres, hasta los espacios de consumo y los personajes principales. Un elemento de valor presente en lo cotidiano es la preparación de comidas, tanto en las fincas habitadas por los propietarios como en las fincas de los propietarios ausentistas donde existen siempre unas alimentadoras que se encargan de esta labor. El espacio central es la cocina, grande por lo general, con fogón de leña, estufa a gas o eléctrica. Las mujeres son el pilar de la cocina y las que más detalles cuentan sobre los platos: "Nos han levantado con sancocho, frijoles, arepa, mazamorra, y también sancocho". Siguen estando presentes los platos e ingredientes tradicionales, altamente valorados, como arepa, mazamorra, carne, papa, plátano, yuca para el sancocho o las preparaciones de los frijoles, con plátano, cidra o col.

La alimentación no solo cubre las necesidades, sino que da ritmo y estructura al día, da seguridad y rutina. La culinaria se convierte también en pretexto 
para las reuniones familiares. En torno a la comida se reúne la familia, se recuerda, se comparte, se cuentan historias, se habla de política y a veces se entona música, como atestiguan varios de los entrevistados (Elisa, Finca La P./P., F74 y su hijo, M56): "La familia se integra con frecuencia, la tradición de estos 'países cantineros' es la comida, la sazón de ella [su madre] es el sancocho, los frijoles campesinos, la cidra, esto es gastronomía del Tolima, de la abuela y bisabuela. [...] Esta tradición tolimense es la comida y la música". No obstante, en los hogares más humildes no era frecuente la fiesta. Guenta Amanda (Finca EL E./P., F65) que los padres "eran muy simples, sin fiestas, los hombres muy machistas, entonces no hubo de esto [música]". En las familias prestantes era más común encontrar una vitrola, un radio o facilidad para contratar músicos.

En un sentido amplio, los cafeteros mismos interpretan su cultura como quehacer, saber y ser. "La cultura, la somos nosotros [sic]", se refiere precisamente al quehacer diario en torno al café y la finca. Emilio adiciona: "La cultura cafetera, qué le dijera yo, pues el café ha traído tantos beneficios y tantos problemas porque cuando la bonanza cafetera nosotros recibimos muchos beneficios". La cultura, según Paola (Finca s./C., F52), es práctica cotidiana, "obligaciones, normalidad, funciones, formas de interactuar. ¡Nosotros somos esto! No es una cosa que nos dieran en un curso como del paisaje cultural cafetero, es lo que nosotros hemos vivido siempre. Es lo normal, lo que somos". Los valores de esta cultura cafetera se encuentran en el diario vivir: la reciprocidad, la laboriosidad, "la cultura, esto son las características del cafetero, los valores son lo que hacemos día a día”.

En resumen, se destaca lo intangible de la cultura reconocida como quehacer diario. El ritmo de vida, la cocina, la convivencia y las prácticas culturales dictan las reglas en este componente. Esto contrasta en cierta medida con "la cultura cafetera inventada que se promueve en los discursos oficiales", como comentan algunos entrevistados. Ahora bien, si la cultura está en la práctica productiva, en las relaciones sociales y en la relación con el entorno natural, como se sostiene, el abandono del campo y de la producción cafetera llevarán indudablemente a la pérdida de la cultura cafetera y por ende del paisaje cafetero. Para mantener los valores patrimoniales hay que mantener población rural activa, sociable, productiva: son estas biografias las que sustentan el paisaje cultural cafetero.

\subsection{El paisaje es el entorno social y familiar}

Los lazos afectivos que tienen los cafeteros de tradición con sus entornos inmediatos están basados en las familiaridades que en estos espacios vecindales se crearon a lo largo de los años. En el primer nivel, la vivienda, se encuentra la familia, elemento valorado que se asocia con el calor humano y la convivencia, que cubre la necesidad de emoción y sentimientos y que es el nodo inicial de los valores sociales compartidos. La familia, de acuerdo con los entrevistados, conforma el hogar, un espacio donde convergen los valores, los cuales se producen, reproducen, rechazan y modifican y dan lugar a una vida social. La centralidad de la familia tiene que ver con el rol dominante de las mujeres al interior de las casas, ellas mantienen la unión a partir del matriarcado ${ }^{4}$. Este liderazgo se muestra en la dominancia, fortaleza e independencia de las mujeres como cabeza de hogar y de la finca, como asegura José, hijo de Elisa: "Esto ha sido sobre todo un matriarcado, mi mamá se separó y nos crio prácticamente sola. Ella ha sido muy dominante y sigue siendo el centro de nuestra familia". El compromiso con la finca y la familia se extiende a los que viven en migración. Es importante destacar que muchas familias tienen miembros de parentesco en otros países y mantienen comunicación y sentido de unidad familiar. Estos migrantes aportan con bienes y servicios

4 Este aspecto destaca en la muestra, ya que evidencia estructuras familiares más allá de la familia nuclear biparental y patriarcal destacada comúnmente en los estudios sobre el campesinado cafetero. 
y apoyan la comercialización del café especial en ciudades capitales o en el exterior.

Ser familia del campo es un distintivo de los demás, los citadinos; es un valor que enfatiza Gustavo (Finca A./P., M59): "Somos familia de campo. Toda la vida vivimos de la finca cafetera". Destacar la procedencia del campo es motivo de orgullo, resistencia, lucha por un reconocimiento poco logrado y hoy se asume a veces con resignación.

En el segundo nivel, la familiaridad, ser familiar de y con los demás, impregna las relaciones vecindales por compartir valores sociales que estructuran la vida en el campo y facilitan la organización social que nace del origen de las veredas: "Toda esta vereda era de una sola familia, todos somos una familia". La familiaridad, efectivamente, es importante para la permanencia en el campo, porque de ahí surgen las redes de apoyo. Compartir un espacio significa conocerse el uno al otro, saludar, intercambiar, mantener contacto, ser familiar con los demás y colaborar, como indica Elisa (Finca La P./P., F76): "Si vienen a pedir un favor, con mucho gusto se lo presta". La sociabilidad entre vecinos, la humildad, la reciprocidad y la transparencia están asociadas con los gustos por el campo: "siempre me ha gustado el campo" es una frase que se repite mucho.

En el tercer nivel están las instituciones como la escuela, muy valorada porque incurrió en la reorientación de la vida del campo, y la institucionalidad cafetera, amada y rechazada, pero necesaria en el apoyo a los caficultores que se encuentran hoy con muchas restricciones y limitaciones. Frente a la multiplicidad de intervenciones de otras entidades sin coordinación, hay un tenor común que califica la institucionalidad rural en las zonas estudiadas como inoperante y coercitiva. Es común escuchar: "Aquí no se colabora a la gente del campo, nunca se han preocupado por el campo". Frente a este escenario, algunos caficultores empezaron a organizarse de acuerdo con sus necesidades e intereses en nuevas formas de asociatividad, donde tienen un rol importante las mujeres como Alicia (Finca L.C./P., F72), que se vinculó con las mujeres cafeteras y la asociación campesina del municipio.

La familia, según lo encontrado en esta investigación, conforma una comunidad de valores compartidos que supera la función laboral y la tradicional composición familiar, en consecuencia, es útil y motivo para conservar la finca, se valora y se comprende su importancia. La familiaridad, la sociabilidad y la solidaridad entre vecinos aún están presentes en la búsqueda de soluciones en común, son estas relaciones sociales las que dan vida al paisaje, son los actores y actos que otorgan significado a los bienes culturales y sentido al paisaje, razón por la cual la participación de sus habitantes es fundamental para una gestión sostenible del patrimonio (Guerrero Valdebenito, 2014). Sin embargo, la población rural ha tenido hasta ahora un rol marginal en la activación patrimonial del paisaje cafetero y se le impusieron cambios por políticas sectoriales, sin considerar la dimensión social y cultural del patrimonio ni los ritmos de la vida rural y sus formas de pensar.

\subsection{El paisaje es vida en transformación, expresión de lo social y estético}

El paisaje vivido (Gómez Rojas, 2006) es tal vez la expresión más completa del paisaje de los cafeteros de tradición. Las narraciones denotan un espacio de proximidad en el cual suceden los eventos y cambios que se acomodan y adaptan a las circunstancias. Los lazos que unen el grupo al lugar, a una tradición y una forma de ser, se tornan visibles cuando se alteran, cuando se destruyen o modifican. Las familias de tradición cafetera observan estos cambios en su entorno con cierta nostalgia, especialmente en lo que concierne la composición social de las veredas: "Todo esto se vendió, pasó a manos ajenas", con lo cual el paisaje pasa de ser semipúblico, con sus caminos y atajos, a un espacio privado, encerrado y excluyente. Emilio 
advierte que "las expectativas para el campo son un poco oscuras porque esta generación que se está levantando no se va a quedar en el campo".

El "disfrute estético de los campesinos en su relación con el paisaje y con la naturaleza" les permite trascender el espacio de la casa y establecer una particular relación con la naturaleza (Concheiro \& Quintana, 2002, citado en Matijasevic Arcila, 2015, p. 124). Así mismo, refleja las formas y las filosofías de vida que hoy se combinan con el gusto por una vida más tranquila, con menos estrés, con productos limpios, con ideales de protección de recursos naturales y oportunidades rurales. La contemplación, la admiración y el disfrute estético de los paisajes rurales se aprecian en la conversación con Luz (Finca E.M./P., F/48) y otros cafeteros: "El paisaje es el paraíso. Para relajarme tomo un tinto y miro para allá. Los pájaros, los animales, mariposas, las flores, para mí es un goce". El paisaje se asocia con flora y fauna, con agua y belleza, con olores y sabores, y con la fe, con algo mayor, el paisaje es vida, aire puro, es una forma de vivir.

Otros, como José (Finca E.B./C., M58), consideran el paisaje como patrimonio más funcional y con miras en los beneficios que puede traer el turismo: "Es muy bonito, pero no más. Es una cosa que siempre estaba ahí, nunca se le ha visto. No pienso que el paisaje tenga beneficios. El recorrido de café, pues, es una cuestión de precios". Desde esta mirada, los cafeteros con fincas grandes consideran el paisaje con miras a su función productiva y los beneficios que puede traer el turismo.

En estas afirmaciones se reflejan las distintas formas y filosofías de vida. De todos modos, el cambio de uso de suelo, las parcelaciones, el abandono del café y el cierre de caminos rurales inciden directamente en las vivencias de los habitantes rurales. Esto se torna conflictivo en la medida en que se desprecia o se menosprecia a los habitantes tradicionales, situación que muestra la creciente estratificación y la presión de intereses diversos en las zonas estudiadas.

\section{Conclusiones}

Como se pudo evidenciar, los vínculos que los cafeteros establecen con el paisaje provienen de diferentes ámbitos: espacial, histórico, social, cultural y productivo. El paisaje, por lo tanto, es más que el sustrato espacial y las condiciones físicas visuales, además se configura por un patrón cultural con códigos culturales. Las experiencias cotidianas y las nociones del paisaje de los cafeteros entrevistados pueden ser punto de partida para acciones de protección patrimonial. Las estrategias patrimoniales deben copiar las estrategias de la vida cotidiana, ya que a partir de estas se encauza un proceso de asimilación, interpretación, transformación, actualización y modificación de lo que constituye la cultura. Conservar el patrimonio de las fincas cafeteras es conservar las condiciones "vivibles" en las cuales se desarrollan los procesos patrimoniales, es fomentar el capital social y cultural que permita formar un arraigo histórico-espacial y procesos productivos y sociales que sustenten las fincas.

Ahora bien, los procesos de apropiación se mueven entre tradición y modernidad, lo que implica entender que la tradición se transforma en una negociación permanente entre los integrantes de una familia. Estas negociaciones ponen a prueba las convivencias y los lineamientos morales y éticos del mismo grupo social. Conservar y reivindicar las estructuras socioculturales, las relaciones de poder y las creencias en proceso permanente de negociaciones intra e intergeneracionales es precisamente una forma de ralentizar los cambios que se realizan en el hogar. Es ahí, con un mayor ejercicio democrático al interior de las relaciones familiares, sociales e institucionales, que se puede contribuir a la conservación de las fincas cafeteras como patrimonio.

Frente a este escenario, se requieren programas que recuperen el valor del campo como espacio de trabajo, vida y hogar en el sentido de Heimat o home (Duncan \& Lambert, 2004; Anton \& Lawrence, 2014) relacionado con racionalidades y lógicas propias de 
la vida rural sobre las cuales no se debe actuar con políticas sectoriales, que suprimen las relaciones entre cultura, producción cafetera, vínculos sociales y patrimonio, sino con políticas integrales que destacan el valor del hogar y la finca como centro de la vida. La mirada acerca de la cotidianidad permite incluir las perspectivas morales y experienciales de los habitantes en la gestión territorial y patrimonial, perspectiva que supera las recetas utilitarias enfocadas en el valor económico del suelo o la asignación de funciones residenciales, residuales o ambientales al espacio rural. Esto implica una política adaptada a las necesidades de los habitantes en las fincas.

Los cafeteros, como grupo social, tienen una identidad que es importante en los procesos de conservación patrimonial. Cualquiera que sea la identidad cultural, tiene que ver con relaciones de poder y reclamos de autonomía que buscan un dominio sobre el paisaje y una participación que va más allá de la participación consultiva. Mantener el patrimonio cafetero en este contexto es reafirmar su existencia y sus valores, es manifestar resiliencia ante los cambios en reclamo de un reconocimiento de las tradiciones, las costumbres y la producción cafetera como elemento central de su cultura. En ciertos casos, una identidad politizada puede llevar a los actores a reivindicar sus valores en una acción afirmadora de su propia condición, como se pudo observar en el caso de las mujeres cafeteras organizadas.

Hoy en día, el tradicional rol de la familia en la comunidad rural se extiende a espacios e intereses más allá de la vereda. Es así como las diferentes iniciativas asociativas evidencian un nuevo capital social que se conforma a partir de personas que han adquirido experiencias y aprendizajes en otros escenarios. Esta condición permite, más allá de la participación social, trazar un desarrollo propio, local y rural, a partir de la integración en "comunidades de sentidos". De esta forma, a partir de las nuevas estructuras sociales se deben replantear estrategias de desarrollo local desde las instituciones respetando capacidades, saberes y relaciones para generar procesos más integrales y participativos que permitan una mayor sostenibilidad.

El modelo de la caficultura parece, para unos, anclado en el pasado, refractario, pero no es inmutable ni invulnerable al paso del tiempo. El trabajo cafetero, ante la incorporación de las mujeres en la vida laboral, el desinterés de los hijos y la gentrificación del campo tiende a modificarse y adaptarse a la disponibilidad de mano de obra y recursos. Mantener el ritmo y la lógica del trabajo cafetero es difícil en condiciones adversas, pero mitiga las perturbaciones en la vida rural. Entonces, trabajar el café responde a una necesidad de mantener la tierra y la vivienda, valores simbólicos y beneficios que aportan bienestar y sostienen la finca cafetera como una forma de patrimonio. La patrimonialización, por su parte, promueve la conversión de la caficultura en objeto patrimonial sin disponer recursos para su mantenimiento, prometiendo proyectos turísticos que tergiversan la cultura, musealizan las fincas y glorifican la bonanza cafetera. En esta representación identitaria, al parecer, basta con apoyarse en imaginarios y representaciones desprovistas de contextos reales y futuros posibles. La conservación del patrimonio, no obstante, debe estar acompañada por programas del Estado que aporten para mejorar las condiciones en las cuales se ha creado este patrimonio agrícola, con un enfoque holístico y procesual en torno al café y que integre la visión de los habitantes. Esto implica modelos diferenciados en la producción del café, la generación de valor agregado en sus productos, la dignificación del campesino y un reconocimiento de los servicios ambientales y culturales que prestan los cafeteros para el paisaje. Las decisiones políticas, de este modo, deben superar las brechas entre los símbolos del pasado y la realidad sociocultural de las zonas patrimoniales, responder a las necesidades de las comunidades y ajustar las políticas tributarias y productivas que marginalizan al cafetero.

Finalmente, el paisaje exige una planificación y gestión territorial con aproximaciones participativas que permitan negociar el uso de los espacios acorde 
a las necesidades y las condiciones de las poblaciones rurales. La aproximación al paisaje se debe plantear desde los acervos culturales, simbólicos e intelectuales de los grupos sociales en el marco del ordenamiento territorial y las políticas de suelo. Esto significa integrar una conciencia paisajística que responda en sus planteamientos al derecho al paisaje, tanto para habitantes como para visitantes.

Enfatizar la gestión del paisaje centrándose en los actores implica reconocer que lo patrimonial existe en la medida en que es soportado, asumido y apropiado por un sujeto que lo reconoce, valora, usa y, por ende, protege como tal, es decir, el patrimonio en tanto relación social y proceso cultural (Smith, 2006). La ausencia de esta condición en la gestión del patrimonio anula progresivamente el valor de los espacios patrimoniales como símbolos de identificación colectiva (Guerrero Valdebenito, 2014). En este escenario, la vitalidad del paisaje debe pensarse desde las formas y los matices de apropiación de sus habitantes, desde los valores ideales y materiales, desde las funciones y los usos del patrimonio para sus habitantes, en fin, desde su dimensión humana-emocional.

\section{Referencias}

Adad, L. D. (2010). Patrimonio, identidad y desarrollo: breve ensayo sobre los procesos de valoración, apropiación y usos del patrimonio cultural, Newesletter, 15. http://www.soc.unicen.edu.ar/index.php/newsletter/82-newsletter/n15/444-articulo-adad

Anton, Ch. \& Lawrence, C. (2014). Home is where the heart is: The effect of place of residence on place attachment and community participation. Journal of Environmental Psychology, 40, 451-461.

Bernasconi, O. (2011). Aproximación narrativa al estudio de fenómenos sociales: principales líneas de desarrollo. Acta Sociológica, 56, 9-36.

Berque, A. (1997). En el origen del paisaje. Revista de Occidente, 189, 7-21.

Bourdieu, P. (1988). Cosas dichas. Gedisa.

Cano Suñén, N. (2011). Miradas y tensiones en los paisajes del Valle de Carranza. [Tesis doctoral]. Departamento de
Filosofía de los Valores y Antropología Social, Universidad del País Vasco.

Caraballo, G. (2011). Valores patrimoniales. Hacia un manejo integral y participativo. En: Patrimonio cultural: un enfoque diverso y comprometido (pp. 25-42). Unesco.

Castillo Ruiz, J. (2015). El patrimonio agrario: razones para su reconocimiento y protección. Desmontando prejuicios, resistencias y menosprecio. En: J. Castillo Ruiz \& C. Martínez Yáñez (coords.), El patrimonio agrario: la construcción cultural del territorio a través de la actividad agraria (pp. 21-72). Universidad Internacional de Andalucía.

Cirvini, S. (2019). El valor del pasado. Aportes para la evaluación del patrimonio arquitectónico en Argentina. Revista de Historia Americana y Argentina, 54(2), 13-38.

Cornejo, M. (2006). El enfoque biográfico: trayectorias, desarrollos teóricos y perspectivas. Psykhe, 15(1), 95-106.

Duis, U. (2007). Plan de Manejo del Paisaje cultural Cafetero. Lineamientos a partir de una metodología participativa de valoración social y cultural. Universidad del Quindío.

Duis, U. (2009). Socialización de los avances del proyecto Paisaje Cultural Cafetero y valoración social del patrimonio en paisajes culturales. CEIR; Universidad del Quindío.

Duis, U. (2020). El café en las venas. Valores patrimoniales de los caficultores del Quindio - De los significados y sentidos de las fincas cafeteras que sustentan el paisaje cultural cafetero. [Tesis de maestría]. Universidad de Caldas.

Duis, U., Saldarriaga, C., \& Parra, D. (2010). Modelo de Integración - Plan de Manejo del Paisaje Cultural Cafetero en el Ordenamiento Territorial. Red Alma Mater; UTP.

Duncan, J. S. \& Lambert, D. (2004). Landscapes of Home. In: J. S. Duncan, N. C. Johnson \& R. H. Schein (eds.), Landscape of home. A Companion to Cultural Geography (pp. 382-403). Blackwell publishing.

Fernández Salinas, V. \& Silva Pérez, R. (2016). Deconstruyendo los paisajes culturales de la Lista del Patrimonio Mundial de la Unesco. Cuadernos Geográficos, 55(1), 176-197.

Folch, R. \& Bru, J. (2017). Ambiente, territorio y paisaje. Valores y valoraciones. Barcino.

Geertz, C. (1973). La interpretación de las culturas. Gedisa editorial.

Gómez Rojas, J. C. (2006). El espacio vivido, una geografía para la vida. En: C. Contreras \& A. B. Narváez (coords.), La experiencia de la ciudad y el trabajo como espacios de vida (pp. 15-43). Colegio de la Frontera Norte; Plaza y Valdés. 
González, P. A. (2015). Conceptualizing Cultural Heritage as a Common. In: P. F. Biehl, D. C. Comer, C. Prescott \& H. A. Soderland (eds.), Identity and Heritage Contemporary Challenges in a Globalized World (pp. 27-35). Springer. doi: https://link.springer.com/chapter/10. 1007\%2F978-3-319-09689-6_3

Guerra, D. \& Skewes, J. C. (2008). ¿Vernacularización, hibridación, enajenación o patrimonialización? Conserva, 12, 5-37.

Guerrero Valdebenito, R. M. (2014). Los habitantes contra el patrimonio mundial: el rol de los habitantes en la gestión de áreas patrimoniales de las ciudades de México y Valparaíso. Apuntes, 27(2), 92-103. https:// repository.javeriana.edu.co/handle/10554/23136

Hernández Romero, Y. \& Galindo Sosa, R. (2007). El concepto de intersubjetividad en Alfred Schütz. Espacios Públicos, 10(20), 228-240.

Hobsbawn, E. \& Ranger, T. (eds.) (1983). The invention of tradition. Cambridge University Press.

Kornblit, A. L. (2007). Metodologías cualitativas en ciencias sociales. Biblos.

Lennon, J. (2002). Values as the basis for management of World Heritage cultural Landscape. In: Unesco World Heritage Centre (ed.), Cultural Landscapes: The Challenges of Conservation (pp. 36-42). World Heritage Papers $n^{\circ} 7$. Unesco.

León Vega, E. (1999). Usos y discursos teóricos sobre la vida cotidiana. Rubí; Anthropos; CRIM (UNAM). https://books. google.com.co/books?id=nsPz7n6ckkcC\&printse$\mathrm{c}=\ldots \& q \& \mathrm{f}$

Llull Peñalba, J. (2005). Evolución del concepto y de la significación social del patrimonio cultural. Revista Arte, Individuo y Sociedad, 17, 175-204. https://revistas.ucm. es/index.php/ARIS/article/view/ARIS0505110177A

Maderuelo, J. (2006). El paisaje, génesis de un concepto. Abada.

Manzini, L. (2011). El significado cultural del patrimonio. Estudios de Patrimonio Cultural, 6, 27-42.

Mármol, C. del, Frigolé, J., \& Narotzky, S. (eds.) (2010). Los lindes del patrimonio. Consumo y valores del pasado. Icaria Institut Català d'Antropologia.

Martínez de Pisón, E. (2010). Valores e identidades en los mapas y sugestión de la toponimia. En: E. Martínez de Pisón \& N. Ortega Cantero (eds.), El paisaje: valores e identidades (pp. 11-46). Fundación Duques de Soria; Universidad Autónoma de Madrid.
Matijasevic Arcila, M. T. (2015). Experiencias de reconocimiento y menosprecio en campesinas y campesinos de Caldas. [Tesis de doctorado]. Centro de Estudios Avanzados en Niñez y Juventud; Universidad de Manizales; CINDE.

Ministerio de Cultura \& Federación Nacional de Cafeteros (FNC) (2009). Plan de Manejo del Paisaje Cultural Cafetero. Ministerio de Cultura \& FNC.

Ministerio de Cultura \& Federación Nacional de Cafeteros (FNC) (2012). Paisaje Cultural Cafetero. Una fusión excepcional de naturaleza, esfuerzo colectivo humano y cultura. [Documento electrónico]. Federación Nacional de Cafeteros de Colombia.

Ministerio de Cultura \& Federación Nacional de Cafeteros (FNC) (2018). Paisaje Cultural Cafetero y Quindío [mapas]. Cartografía básica IGAC, elaborado por FNC, Sistema de Información Cafetero (SICA). Paisaje Cultural Cafetero. http://paisajeculturalcafetero.org.co/ contenido/cartografia-del-pcc

Nogué, J. (2007). La construcción social del paisaje. Biblioteca Nueva.

Ojeda Rivera, J. F. (2013). Lectura transdisciplinar de paisajes cotidianos, hacia una valoración patrimonial. Método de aproximación. Revista INVI, 28(78), 27-75.

Prats, Ll. \& Santana, A. (2005). Reflexiones libérrimas sobre patrimonio, turismo y sus confusas relaciones. En: Ll. Prats \& A. Santana (coord.), El encuentro del turismo con el patrimonio cultural. Concepciones teóricas y modelos de aplicación (pp. 9-25). Fundación El Monte.

Querejazu Leyton, P. (2003). La apropiación social del patrimonio. En: Convenio Andrés Bello (ed.), Somos Patrimonio: 144 experiencias de apropiación social del patrimonio cultural y natural. III Concurso Somos Patrimonio (pp. 19-25). Unidad editorial CAB.

Reguillo, R. (2000). La clandestina centralidad de la vida cotidiana. En: A. Lindón (coord.), La vida cotidiana y su espacio-temporalidad (pp. 77-94). Rubí; Anthropos; El Colegio Mexiquense; CRIM.

Sepúlveda Manterola, J. S. (2004). Barrio, comunidad y patrimonio cultural. Un estudio cualitativo sobre los habitantes de los cerros Alegre y Concepción de Valparaíso. [Tesis de grado]. Universidad de Chile.

Sereno, G. A. (2020). Anclajes territoriales en un espacio de borde: el caso del rururbano de la ciudad de Bahía Blanca (Buenos Aires, Argentina). Perspectiva Geográfica, 25(2), 56-78. 
Silva Pérez, R. (2009). Agricultura, paisaje y patrimonio territorial. Los paisajes de la agricultura vistos como patrimonio. Boletín de la Asociación de Geógrafos Españoles, 49, 309-334.

Smith, L. (2006). Uses of Heritage. Routledge.
Ulloa, A. (2002). De una naturaleza dual a la proliferación de sentido: la discusión antropológica en torno a la naturaleza, la ecología y el medio ambiente. En: G. Palacio \& A. Ulloa A. (eds.), Repensando la naturaleza. Encuentros y desencuentros disciplinarios en torno a lo ambiental (pp. 139-154). Universidad Nacional de Colombia, sede Leticia; IMANI; ICANH; Colciencias. 